\title{
Comparing Visual Acuity, Low Contrast Acuity and Contrast Sensitivity After Trifocal Toric and Extended Depth of Focus Toric Intraocular Lens Implantation
}

This article was published in the following Dove Press journal:

Clinical Ophthalmology

\section{Kjell G Gundersen (iD) Rick Potvin (1D ${ }^{2}$}

'IFocus Øyeklinikk AS, Haugesund, Norway; ${ }^{2}$ Science in Vision, Akron, NY, USA
Correspondence: Kjell G Gundersen IFocus Øyeklinikk AS, Haugesund 5527, Norway

Tel +475808900

Email kg@ifocus.no
Purpose: The aim of this study was to compare visual acuity at various distances (far, intermediate and near), low contrast acuity and contrast sensitivity after trifocal toric and extended depth of focus (EDOF) toric intraocular lens (IOL) implantation.

Patients and Methods: This was a non-interventional two-arm comparative study of visual outcomes after uncomplicated bilateral cataract or refractive lens exchange surgery with IOL implantation between 6 months and 5 years before a single diagnostic examination visit. There was no masking and no control group. Subjects had to have uncorrected distance visual acuity (UDVA) of 20/40 (0.3 logMAR) or better measured at the time of their study visit. Clinical evaluations included the manifest refraction, visual acuity (VA) at distance, intermediate $(60 \mathrm{~cm})$ and near $(40 \mathrm{~cm})$, low contrast $(10 \%)$ VA and contrast sensitivity.

Results: A total of 50 bilaterally implanted patients (25 trifocal, 25 EDOF) were examined; the two groups had similar characteristics, including corneal astigmatism. Postoperative refractive outcomes were also similar. There were no statistically significant differences in distance or intermediate VA between groups, but the trifocal group had significantly better near VA both uncorrected $(\mathrm{p}=0.009)$ and distance-corrected $(\mathrm{p}=0.014)$. There were no statistically significant differences in the low contrast acuity measures between IOLs at either distance or $40 \mathrm{~cm}$, with or without glare. Contrast sensitivity in mesopic and photopic conditions was similar.

Conclusion: The trifocal and EDOF toric IOLs performed similarly for all measures except near VA, where the trifocal toric provided significantly better acuity. For subjects interested in reducing spectacle independence at near, this may be an important consideration.

Keywords: trifocal toric, EDOF toric, low contrast acuity, contrast sensitivity, presbyopia correction

\section{Plain Language Summary}

After cataract surgery, patients typically have an intraocular lens (IOL) implanted, usually chosen to provide clear vision at distance. Some IOLs can also provide better vision for intermediate (computer) and near (reading) work. IOLs called toric IOLs can also correct astigmatism. The IOLs studied here were designed to provide vision at distance, intermediate and near AND to correct astigmatism. One of them was an Extended Depth of Focus IOL. It sacrifices a super-sharp image at one point to provide a slightly less sharp image across a range of distances. There is a limit to how much the depth of focus can be extended, so these lenses can have good intermediate but slightly worse vision at near. Their reported advantage 
is that they split light to stretch one focal point, rather than creating distinct focal points. A trifocal IOL splits the incoming light to produce 3 distinct focal points. Visual acuity at those points is expected to be good, but there is a slightly higher potential for glare and halos.

We tested two sets of subjects, one set with the EDOF toric and the other with the trifocal toric. Vision was checked at distance, intermediate and near. The ability to see low contrast letters (gray on white, instead of black on white) was also tested, along with contrast sensitivity (a measure of visual quality). The two groups were very similar, with the same level of visual disturbances. However, the trifocal toric IOL provided significantly better near vision.

\section{Introduction}

The most common intraocular lenses (IOLs) implanted during cataract surgery are monofocal IOLs. This type of lens provides good vision at distance, but patients will remain dependent on spectacles to see clearly at other focal points, such as at near when reading and at intermediate when using a computer. Bifocal IOLs attempt to alleviate spectacle dependence by providing good visual performance at distance and near, but intermediate vision can still be compromised. ${ }^{1}$ Suitable alternatives for presbyopic correction are trifocal and extended depth of focus (EDOF) IOLs, which aim to provide effective visual performance across all ranges - near, intermediate, and far.

The AcrySof ${ }^{\circledR}$ PanOptix ${ }^{\circledR}$ IOL (Alcon Laboratories, Inc., Fort Worth, TX, USA) is a commonly used trifocal IOL and is the only trifocal IOL currently approved by the US FDA. It is actually a quadrafocal, but functionally uses 3 points of focus for clear vision at all ranges-near $(40 \mathrm{~cm})$, intermediate $(60 \mathrm{~cm})$, and distance. ${ }^{2}$ It is designed as a diffractive aspheric optical and adds $-0.10 \mu \mathrm{m}$ of spherical aberration to compensate for the net positive spherical aberration from the cornea. ${ }^{3}$ There is evidence to show that this IOL provides good vision across a range of distances. A recent study by Alfonso et $\mathrm{al}^{4}$ found that $100 \%$ of patients had uncorrected visual acuities of 20/40 or better at $30 \mathrm{~cm}, 40 \mathrm{~cm}, 50 \mathrm{~cm}, 60 \mathrm{~cm}, 70 \mathrm{~cm}$, and distance 6 months postoperatively. Other studies have also shown that postoperative visual acuities at near, intermediate, and far with the PanOptix Trifocal IOL are good. ${ }^{5-9}$ Despite the good visual acuity in these trifocal IOLs, visual disturbances can occur due to the light being split to create distinct focal points. Disturbances such as glare and halos are possible, and reduced contrast sensitivity has been reported relative to monofocal IOLs. ${ }^{10,11}$
The Tecnis Symfony ${ }^{\circledR}$ (J\&J Vision, Inc., Santa Ana, CA, USA) is a widely used EDOF IOL. Rather than creating distinct focal points, the IOL uses diffractive echelettes to elongate the depth of focus to increase a patient's range of vision. These diffractive echelettes also decrease chromatic aberration, which is expected to potentially improve contrast sensitivity. ${ }^{12}$ The IOL also adds $-0.27 \mu \mathrm{m}$ of spherical aberration to counterbalance net positive spherical aberration from the cornea. ${ }^{13}$ Kohnen et $\mathrm{al}^{14}$ recently reported that average patient uncorrected visual acuity was $0.22 \log$ MAR or better at $40 \mathrm{~cm}, 60 \mathrm{~cm}$, $80 \mathrm{~cm}$, and distance. Good performance with the Tecnis Symfony IOL has also been reported in other studies. ${ }^{15-23}$ A potential benefit of EDOF IOLs compared to bifocal and trifocal IOLs is that visual disturbances may be reduced. This is because EDOF IOLs split light in a more continuous fashion, stretching a specific focal point rather producing several distinct focal points. There are limits to this ability to extend the depth of focus, so these lenses are often reported to have worse near vision relative to bifocals or trifocals. While visual disturbances are expected to be less with an EDOF IOL relative to a multifocal IOL, starbursts and halos have been reported. ${ }^{24-26}$

Although trifocal and EDOF IOLs provide good visual outcomes, their performance can be significantly reduced by residual astigmatism. Corneal astigmatism of $1 \mathrm{D}$ or more occurs in approximately $40 \%$ of cataract patients, ${ }^{27}$ which if left uncorrected decreases patient satisfaction postoperatively. ${ }^{28}$ Residual astigmatism can be corrected with corneal refractive surgery, arcuate partial-depth incisions or toric IOLs. ${ }^{29-32}$ Toric IOLs have been shown to have greater predictability and are often the preferred option over corneal arcuate incisions, particularly at higher levels of corneal astigmatism. ${ }^{33,34}$

Recent studies have directly compared the AcrySof PanOptix and the Tecnis Symfony IOLs. ${ }^{3,13,35-38}$ However, there are no published studies directly comparing only trifocal toric and EDOF toric IOLs. The purpose of this study was to compare visual acuity, low contrast acuity and contrast sensitivity after bilateral implantation of either the trifocal toric or the EDOF toric IOL.

\section{Patients and Methods}

This study was a non-interventional two-arm comparative study of visual outcomes after successful bilateral cataract surgery or refractive lens exchange surgery with IOL implantation. Regional ethics committee approval was applied for and obtained before patients were enrolled 
(REK, Norway). Patients signed an appropriate informed consent document. As the study was non-interventional there was no requirement to register it as a clinical trial. The study was conducted in accordance with the tenets of the Declaration of Helsinki. A statistical power analysis related to the ability to detect a half-line difference in near VA, with a power of 0.8 and an alpha of 0.05 , indicated that 24 subjects in each group would be sufficient. Patients who had uncomplicated bilateral cataract surgery between 6 months and 5 years before their examination visit were eligible for inclusion; subjects were assessed during a single diagnostic visit. There was no masking and no control group.

Eligible test subjects had previous uncomplicated bilateral implantation of toric trifocal or toric EDOF IOLs, based on the patient's interest in a higher degree of spectacle freedom at far, intermediate and near distances after IOL implantation. They had to have uncorrected binocular and monocular distance visual acuity of 20/40 (0.3 $\log$ MAR $)$ or better measured at the time of their study visit and have good ocular health, with no pathology that compromises visual acuity (outside of residual refractive error). Subjects with prior corneal refractive or other surgery were excluded. Cataract surgery for all subjects had been performed by one surgeon (KGG). The Verion ${ }^{\mathrm{TM}}$ Image Guided System (Alcon, Fort Worth TX, USA) was used for toric IOL alignment.

Clinical evaluations included the manifest refraction, visual acuity (VA) at distance, intermediate $(60 \mathrm{~cm})$ and near $(40 \mathrm{~cm})$, low contrast $(10 \%)$ VA and contrast sensitivity. All vision testing was performed using the $M \& S$ Technologies Clinical Trial Suite (Niles, IL, USA). One optometrist completed all subject examinations. The primary measure of interest was the binocular uncorrected near VA. Clinical data were exported to Excel files and imported into Microsoft Access for preliminary analysis (both Microsoft Corp., Redmond, WA, USA). Comparative analyses were performed using the STATISTICA data analysis software system, version 12 (TIBCO Software Inc., Palo Alto, CA, USA); analysis of variance (ANOVA) was used to compare continuous variables and the Chi-squared test was used to compare nonparametric variables, with statistical significance based on $\mathrm{p}=0.05$.

\section{Results}

A total of 50 bilaterally implanted patients ( 25 trifocal, 25 EDOF) who met the inclusion criteria were identified and examined. Table 1 shows the demographic data by subject for the two groups, along with the relevant preoperative biometry by the group. Subjects were reasonably well matched for age, sex and surgery type (cataract surgery or refractive lens exchange). IOL sphere power was significantly higher in the trifocal group but the difference was considered unlikely to affect overall results. Most importantly, there were no statistically significant differences in the average keratometry or the keratometric cylinder between groups.

The postoperative refractive data by the group are summarized in Table 2. As can be seen, the refractive sphere and spherical equivalent refraction are slightly more hyperopic in the trifocal group, but the mean differences are less than $0.25 \mathrm{D}$ in both cases. The number of eyes with a spherical equivalent refraction within $0.50 \mathrm{D}$ of plano was not significantly different between groups, nor was the number of eyes with $0.50 \mathrm{D}$ or less of refractive cylinder. Ninety percent of eyes in both groups had a residual refractive cylinder $\leq 0.50 \mathrm{D}$.

Figure 1 shows the uncorrected and best distance-corrected binocular VA for the two IOLs at distance, intermediate and near. There were no statistically significant

Table I Subject Demographics and Preoperative Biometry

\begin{tabular}{|l|l|l|l|}
\hline & EDOF & Trifocal & P \\
\hline n (subjects/eyes) & $25 / 50$ & $25 / 50$ & \\
Female/male & $16 / 9$ & $16 / 9$ & \\
Cataract surgery/RLE & $15 / 10$ & $9 / 16$ & 0.08 \\
Age (years) & $61.5 \pm 7.4(48$ to 75$)$ & $59.0 \pm 8.3(50$ to $8 I)$ & 0.26 \\
IOL sphere power (D) & $19.41 \pm 5.25(8.0$ to 30.5$)$ & $22.16 \pm 4.35(12.0$ to 29.0$)$ & 0.01 \\
Average keratometry (D) & $43.48 \pm 1.46(39.90$ to 46.17$)$ & $43.30 \pm 1.92(38.88$ to 47.28$)$ & 0.60 \\
Keratometric cylinder (D) & $1.65 \pm 0.53(0.72$ to 3.08$)$ & $1.7 I \pm 1.02(0.16$ to 4.83$)$ & 0.74 \\
\hline
\end{tabular}

Abbreviations: EDOF, extended depth of focus; RLE, refractive lens exchange; IOL, intraocular lens; D, diopter. 
Table 2 Postoperative Refractive Data by Group

\begin{tabular}{|l|l|l|l|}
\hline & EDOF & Trifocal & p \\
\hline $\mathrm{n}$ & 50 & 50 & \\
Manifest sphere (D) & $0.06 \pm 0.3 \mathrm{I}(-1.00$ to 0.75$)$ & $0.29 \pm 0.35(-0.75$ to 1.25$)$ & $<0.0$ I \\
Manifest cylinder (D) & $0.27 \pm 0.3 \mathrm{I}(0.00$ to I.25) & $0.29 \pm 0.27(0.00$ to 1.25$)$ & 0.73 \\
MRSE (D) & $-0.08 \pm 0.3 \mathrm{I}(-\mathrm{I} .13$ to 0.50$)$ & $0.15 \pm 0.37(-0.88$ to 1.00$)$ & $<0.0 \mathrm{I}$ \\
Eyes with absolute MRSE $\leq 0.50 \mathrm{D}$ & $47(94 \%)$ & $43(86 \%)$ & 0.18 \\
Eyes with $\leq 0.50 \mathrm{D}$ of cylinder & $45(90 \%)$ & $46(92 \%)$ & 0.75 \\
\hline
\end{tabular}

Abbreviations: EDOF, extended depth of focus; MRSE, mean refraction spherical equivalent; IOL, intraocular lens; D, diopter.

differences between the two groups for distance and intermediate vision, but the trifocal IOL provided significantly better near vision in both the uncorrected $(\mathrm{p}=0.009)$ and best distance-corrected $(\mathrm{p}=0.014)$ states. Table 3 provides a summary of the number of eyes with a given VA at a given distance (or at multiple distances).

Figure 2 shows a box-whisker plot of the low contrast $(10 \%)$ visual acuity without glare when tested at distance $(4 \mathrm{~m})$ and near $(40 \mathrm{~cm})$ in photopic and mesopic conditions. There were no statistically significant differences in the low contrast acuity measures between IOLs at either distance for either illumination condition. Low contrast acuity was also tested with a glare target at $4 \mathrm{~m}$ in both photopic and mesopic conditions, but no subject in either group could read any of the letters in either illumination condition.

Figure 3 shows the summary results for the sine wave contrast sensitivity test in photopic and mesopic conditions by the group. There were no statistically significant differences in contrast sensitivity between groups for either test condition at any spatial frequency. At higher spatial frequencies the EDOF lens showed slightly better scores in both mesopic and photopic conditions, but the differences were not statistically significant ( $p>0.14$ in both cases).

\section{Discussion}

To the best of our knowledge, this is the first study to compare the clinical performance and contrast sensitivity

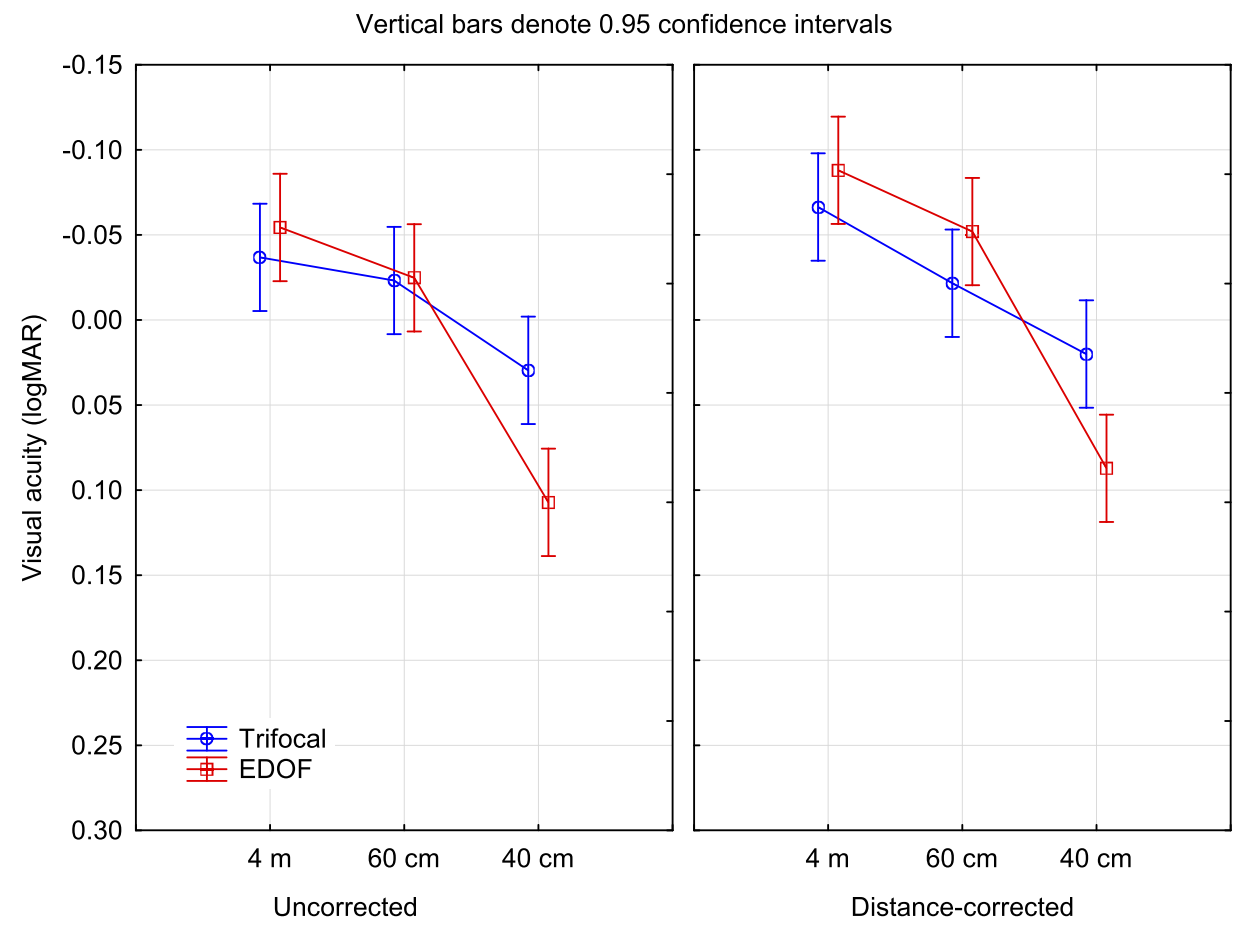

Figure I Binocular visual acuity by IOL group and viewing distance.

Abbreviations: EDOF, extended depth of focus; logMAR, log of the minimum angle of resolution; m, meters; cm, centimeters; IOL, intraocular lens. 
Table 3 Subjects with a Given Binocular VA at the Reported Distance(s) and Correction

\begin{tabular}{|l|l|l|l|l|l|}
\hline Criterion & Distance & Correction & EDOF (n = 25) & Trifocal (n= 25) & $\mathbf{p}$ \\
\hline \multirow{2}{*}{0.1 logMAR (20/25) } & $40 \mathrm{~cm}$ & $\begin{array}{l}\text { Uncorrected } \\
\text { Best distance-corrected }\end{array}$ & $\begin{array}{l}13(52 \%) \\
15(60 \%)\end{array}$ & $\begin{array}{l}22(88 \%) \\
22(88 \%)\end{array}$ & $\begin{array}{l}0.006 \\
0.02\end{array}$ \\
\cline { 2 - 6 } & All distances & $\begin{array}{l}\text { Uncorrected } \\
\text { Best distance-corrected }\end{array}$ & $\begin{array}{l}13(52 \%) \\
15(60 \%)\end{array}$ & $\begin{array}{l}22(88 \%) \\
22(88 \%)\end{array}$ \\
\hline \multirow{2}{*}{0.0 logMAR (20/20) } & $40 \mathrm{~cm}$ & $\begin{array}{l}\text { Uncorrected } \\
\text { Best distance-corrected }\end{array}$ & $\begin{array}{l}3(12 \%) \\
4(16 \%)\end{array}$ & $\begin{array}{l}9(28 \%) \\
12(48 \%)\end{array}$ & $\begin{array}{l}0.006 \\
0.015\end{array}$ \\
\cline { 2 - 6 } & All distances & Uncorrected & $3(12 \%)$ & $5(20 \%)$ \\
& Best distance-corrected & $4(16 \%)$ & $\begin{array}{l}11(44 \%) \\
0.44\end{array}$ \\
\hline
\end{tabular}

Abbreviations: VA, visual acuity; EDOF, extended depth of focus; logMAR, log of the minimum angle of resolution; cm, centimeters.

of this trifocal toric and this EDOF toric IOL up to 60 months after bilateral implantation. Both IOLs generally performed well, with good patient visual acuity. Patient near visual acuity, both uncorrected and corrected was better with the trifocal toric IOL. Other studies comparing the non-toric version of these IOLs showed similar findings. ${ }^{3,35,36,38}$

In contrast to near visual acuity, patient distance (and intermediate) visual acuity were similar for both toric IOLs. This is consistent with the results of Cochener et $\mathrm{al}^{38}$ and

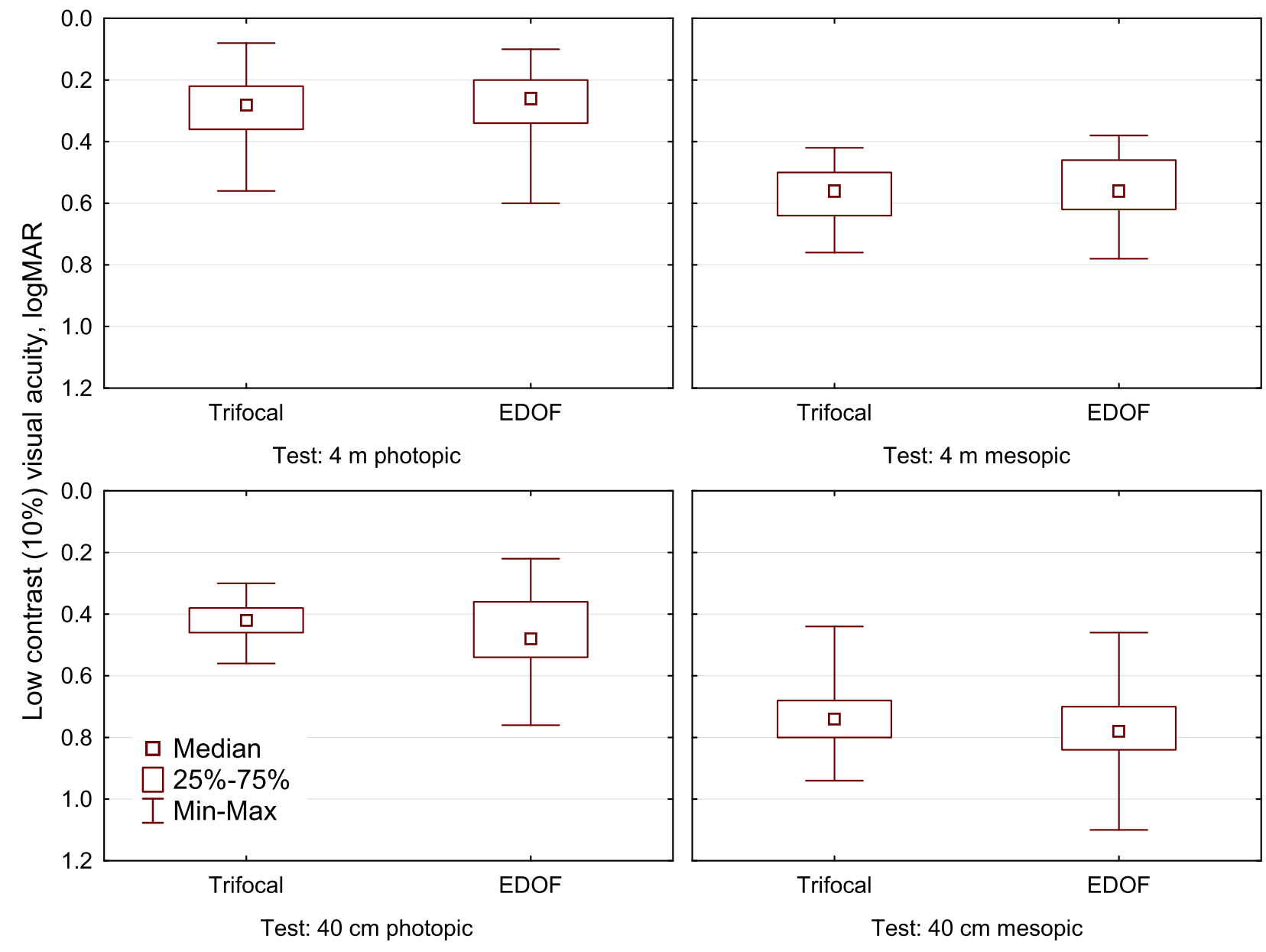

Figure 2 Low contrast (10\%) visual acuity in photopic and mesopic conditions by the IOL group.

Abbreviations: EDOF, extended depth of focus; logMAR, log of the minimum angle of resolution; m, meters; cm, centimeters; Min, minimum; Max, maximum; IOL, intraocular lens. 


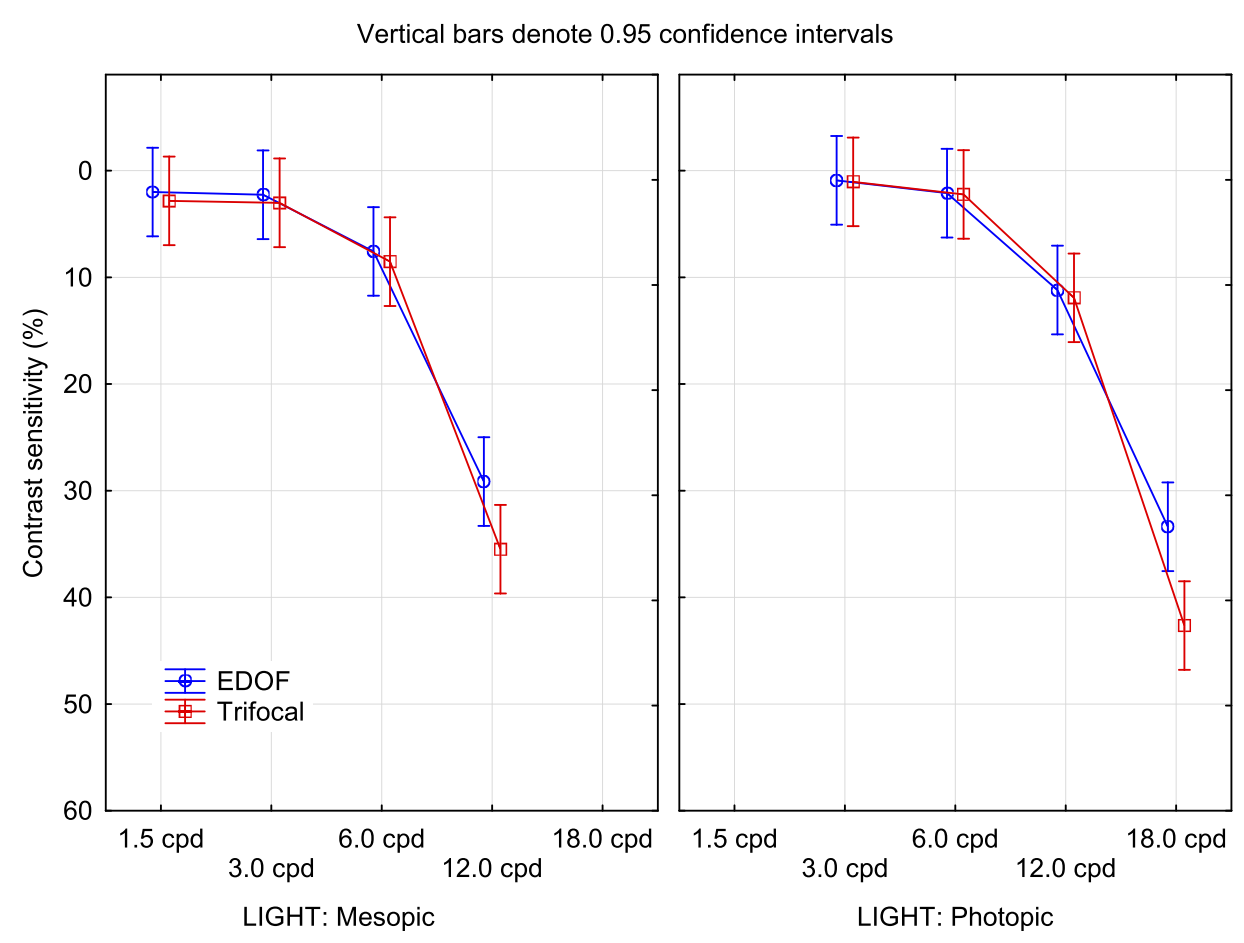

Figure 3 Contrast sensitivity by IOL group and illumination condition.

Abbreviations: EDOF, extended depth of focus; cpd, cycles per degree; IOL, intraocular lens.

Ruiz-Mesa et al. ${ }^{3}$ Some earlier studies reported slightly better distance VA with the EDOF IOL, but we did not find this in our study. ${ }^{35,36}$ We measured intermediate vision at $60 \mathrm{~cm}$ and saw no statistically significant difference between the two toric IOLs. Intermediate VA can be evaluated at varying distances. A recent study by De Medeiros et $\mathrm{al}^{36}$ concluded that patient visual acuity was better with the trifocal from $40 \mathrm{~cm}$ to $67 \mathrm{~cm}$, while patient uncorrected intermediate visual acuity (UIVA) at $70 \mathrm{~cm}$ was superior with the EDOF IOL. Mencucci et $\mathrm{al}^{35}$ reported that average patient UIVA was equivalent when the intermediate target distance was $60 \mathrm{~cm}$ for the trifocal IOL and $80 \mathrm{~cm}$ for the EDOF IOL. Ruiz-Mesa et al reported no or very little difference at intermediate vision $(60 \mathrm{~cm}$ and $80 \mathrm{~cm})$ between the two IOLs. ${ }^{3}$ These intermediate vision findings are consistent with the design features of the two IOLs. An EDOF lens will extend the distance focus as much as can be tolerated, which effectively provides what might be considered a low add. The trifocal studied here is actually a quadrafocal, with the intermediate focus closer to near $(60 \mathrm{~cm}$ instead of the expected $80 \mathrm{~cm}$ for a "true" trifocal). A final important consideration with regard to intermediate vision is the working distance for computers and hand-held devices; simple measurement shows they are typically held between 40 and $60 \mathrm{~cm}$ away.
Contrast sensitivity was also similar between the two toric IOLs. Menucucci et $\mathrm{al}^{35}$ reported that patients with the EDOF IOL had better contrast sensitivity under both photopic and mesopic conditions, but other studies have reported no differences in contrast sensitivity in either photopic or mesopic conditions between these two IOLs. ${ }^{3,38}$

There are limitations to the current study. The number of subjects was limited. The two groups were not randomized, as patients self-selected for the lenses in question at the time of surgery. The inclusion criteria included a required minimum postoperative visual acuity, so these might be considered "best case" results for the two IOLs. Intermediate VA was tested only at $60 \mathrm{~cm}$. Toric stability was not evaluated (though the stable refractive results provide a good indication that rotational stability was not a significant issue for either lens). Finally, while low contrast acuity and contrast sensitivity were measured, as objective tests of visual quality, no subjective evaluations of spectacle independence or visual quality were collected from subjects.

\section{Conclusion}

Both toric IOLs provided good distance and intermediate vision to subjects, with similar low contrast VA and contrast sensitivity. Near vision was significantly better with 
the trifocal toric IOL. This might be a consideration when discussing presbyopia-correcting IOL options at the time of cataract surgery.

\section{Acknowledgments}

Brad Hall, PhD of Sengi, aided in the preparation of this manuscript.

\section{Disclosure}

Drs. Gundersen and Potvin are consultants to and report grants from Alcon. This work was conducted as an investigator-initiated study financed by Alcon. The authors report no other conflicts of interest in this work.

\section{References}

1. Gatinel D, Houbrechts Y. Comparison of bifocal and trifocal diffractive and refractive intraocular lenses using an optical bench. $J$ Cataract Refract Surg. 2013;39(7):1093-1099. doi:10.1016/j. jcrs.2013.01.048

2. Kohnen T. First implantation of a diffractive quadrafocal (trifocal) intraocular lens. $J$ Cataract Refract Surg. 2015;41(10):2330-2332. doi:10.1016/j.jcrs.2015.11.012

3. Ruiz-Mesa R, Abengozar-Vela A, Ruiz-Santos M. A comparative study of the visual outcomes between a new trifocal and an extended depth of focus intraocular lens. Eur J Ophthalmol. 2018;28(2):182187. doi:10.5301/ejo.5001029

4. Alfonso JF, Fernandez-Vega-Cueto L, Fernandez-Vega L, MontesMico R. Visual function after implantation of a presbyopia-correcting trifocal intraocular lens. Ophthalmic Res. 2019;1-13.

5. Alio JL, Plaza-Puche AB, Alio Del Barrio JL, et al. Clinical outcomes with a diffractive trifocal intraocular lens. Eur J Ophthalmol. 2018;28(4):419-424. doi:10.1177/1120672118762231

6. Garcia-Perez JL, Gros-Otero J, Sanchez-Ramos C, Blazquez V, Contreras I. Short term visual outcomes of a new trifocal intraocular lens. BMC Ophthalmol. 2017;17(1):72. doi:10.1186/s12886-017-0462-y

7. Kohnen T, Herzog M, Hemkeppler E, et al. Visual performance of a quadrifocal (Trifocal) intraocular lens following removal of the crystalline lens. Am J Ophthalmol. 2017;184:52-62. doi:10.1016/j.ajo.2017.09.016

8. Lawless M, Hodge C, Reich J, et al. Visual and refractive outcomes following implantation of a new trifocal intraocular lens. Eye Vis (Lond). 2017;4(1):10. doi:10.1186/s40662-017-0076-8

9. Bissen-Miyajima H, Ota Y, Hayashi K, Igarashi C, Sasaki N. Results of a clinical evaluation of a trifocal intraocular lens in Japan. Jpn J Ophthalmol. 2020;64(2):140-149. doi:10.1007/s10384-019-00712-4

10. de Silva SR, Evans JR, Kirthi V, Ziaei M, Leyland M. Multifocal versus monofocal intraocular lenses after cataract extraction. Cochrane Database Syst Rev. 2016;12:CD003169. doi:10.1002/ 14651858.CD003091.pub4

11. Cochener B, Lafuma A, Khoshnood B, Courouve L, Berdeaux G. Comparison of outcomes with multifocal intraocular lenses: a metaanalysis. Clin Ophthalmol. 2011;5:45-56. doi:10.2147/OPTH.S14325

12. Negishi K, Ohnuma K, Hirayama N, Noda T. Policy-based medical services network study group for intraocular L, refractive $\mathrm{S}$. effect of chromatic aberration on contrast sensitivity in pseudophakic eyes. Arch Ophthalmol. 2001;119(8):1154-1158. doi:10.1001/archopht.119.8.1154

13. de Medeiros AL, de Araujo Rolim AG, Motta AFP, et al. Comparison of visual outcomes after bilateral implantation of a diffractive trifocal intraocular lens and blended implantation of an extended depth of focus intraocular lens with a diffractive bifocal intraocular lens. Clin Ophthalmol. 2017;11:1911-1916.
14. Kohnen T, Bohm M, Hemkeppler E, et al. Visual performance of an extended depth of focus intraocular lens for treatment selection. Eye (Lond). 2019;33(10):1556-1563. doi:10.1038/s41433019-0443-x

15. Ferreira TB, Pinheiro J, Zabala L, Ribeiro FJ. Comparative analysis of clinical outcomes of a monofocal and an extended-range-of-vision intraocular lens in eyes with previous myopic laser in situ keratomileusis. J Cataract Refract Surg. 2018;44(2):149-155. doi:10.1016/j. jcrs.2017.11.007

16. Sachdev GS, Ramamurthy S, Sharma U, Dandapani R. Visual outcomes of patients bilaterally implanted with the extended range of vision intraocular lens: a prospective study. Indian J Ophthalmol. 2018;66(3):407-410. doi:10.4103/ijo.IJO_813_17

17. Gundersen KG. Rotational stability and visual performance 3 months after bilateral implantation of a new toric extended range of vision intraocular lens. Clin Ophthalmol. 2018;12:1269-1278. doi:10.2147/ OPTH.S173120

18. Cochener B, Concerto Study G. Clinical outcomes of a new extended range of vision intraocular lens: international multicenter concerto study. J Cataract Refract Surg. 2016;42(9):1268-1275. doi:10.1016/j. jers.2016.06.033

19. Pandit RT. Monocular clinical outcomes and range of near vision following cataract surgery with implantation of an extended depth of focus intraocular lens. J Ophthalmol. 2018;2018:8205824.

20. Pedrotti E, Bruni E, Bonacci E, Badalamenti R, Mastropasqua R, Marchini G. Comparative analysis of the clinical outcomes with a monofocal and an extended range of vision intraocular lens. $J$ Refract Surg. 2016;32(7):436-442. doi:10.3928/1081597X-20160428-06

21. Webers VSC, Bauer NJC, Saelens IEY, et al. Comparison of the intermediate distance of a trifocal IOL with an extended depth-offocus IOL. J Cataract Refract Surg. 2020;46(2):193-203. doi:10. 1097/j.jcrs.0000000000000012

22. Christopher KL, Miller DC, Patnaik JL, Lynch AM, Davidson RS, Taravella MJ. Comparison of visual outcomes of extended depth of focus lenses in patients with and without previous laser refractive surgery. J Refract Surg. 2020;36(1):28-33. doi:10.3928/1081597X20191204-01

23. Schojai M, Schultz T, Corrinna J, Böcker DIJ, Dick HB. Prospective Randomized Comparative Trial: Visual performance comparison of 2 extended depth-of-focus IOLs. J Cataract Refract Surg. 2020;46 (3):388-393. doi: 10.1097/j.jcrs.0000000000000068

24. Cochener B. Influence of the level of monovision on visual outcome with an extended range of vision intraocular lens. Clin Ophthalmol. 2018;12:2305-2312. doi:10.2147/OPTH.S184712

25. Lamba A, Pereira A, Varma D, Shahidi A, Smith D, Ahmed IIK. Retrospective analysis on the visual outcomes and photic phenomena following bilateral extended depth of focus intraocular lens implants. Can J Ophthalmol. 2019. doi:10.1016/j.jcjo.2019.07.024

26. Song X, Liu XIN, Wang WEI, et al. Visual outcome and optical quality after implantation of zonal refractive multifocal and extended range of vision intraocular lenses. J Cataract Refract Surg. 2020;46 (4):540-548. doi:10.1097/j.jcrs.0000000000000088

27. Khan MI, Muhtaseb M. Prevalence of corneal astigmatism in patients having routine cataract surgery at a teaching hospital in the United Kingdom. J Cataract Refract Surg. 2011;37(10):1751-1755. doi:10. 1016/j.jcrs.2011.04.026

28. Hayashi K, Manabe S, Yoshida M, Hayashi H. Effect of astigmatism on visual acuity in eyes with a diffractive multifocal intraocular lens. $J$ Cataract Refract Surg. 2010;36(8):1323-1329. doi:10.1016/j.jcrs. 2010.02.016

29. Thornton SP. Astigmatic keratotomy: a review of basic concepts with case reports. J Cataract Refract Surg. 1990;16(4):430-435. doi:10. 1016/S0886-3350(13)80795-X

30. Budak K, Friedman NJ, Koch DD. Limbal relaxing incisions with cataract surgery. J Cataract Refract Surg. 1998;24(4):503-508. doi:10.1016/S0886-3350(98)80292-7 
31. Norouzi H, Rahmati-Kamel M. Laser in situ keratomileusis for correction of induced astigmatism from cataract surgery. J Refract Surg. 2003;19(4):416-424.

32. Mozayan E, Lee JK. Update on astigmatism management. Curr Opin Ophthalmol. 2014;25(4):286-290. doi:10.1097/ICU.0000000000000068

33. Mingo-Botin D, Munoz-Negrete FJ, Won Kim HR, Morcillo-Laiz R, Rebolleda G, Oblanca N. Comparison of toric intraocular lenses and peripheral corneal relaxing incisions to treat astigmatism during cataract surgery. J Cataract Refract Surg. 2010;36(10):1700-1708. doi:10.1016/j.jcrs.2010.04.043

34. Kessel L, Andresen J, Tendal B, Erngaard D, Flesner P, Hjortdal J. Toric intraocular lenses in the correction of astigmatism during cataract surgery: a systematic review and meta-analysis. Ophthalmology. 2016;123(2):275-286. doi:10.1016/j.ophtha.2015.10.002

35. Mencucci R, Favuzza E, Caporossi O, Savastano A, Rizzo S. Comparative analysis of visual outcomes, reading skills, contrast sensitivity, and patient satisfaction with two models of trifocal diffractive intraocular lenses and an extended range of vision intraocular lens. Graefes Arch Clin Exp Ophthalmol. 2018;256(10):1913-1922. doi:10.1007/s00417-018-4052-3
36. de Medeiros AL, Jones Saraiva F, Iguma CI, et al. Comparison of visual outcomes after bilateral implantation of two intraocular lenses with distinct diffractive optics. Clin Ophthalmol. 2019;13:16571663.

37. Liu J, Dong Y, Wang Y. Efficacy and safety of extended depth of focus intraocular lenses in cataract surgery: a systematic review and meta-analysis. BMC Ophthalmol. 2019;19(1):198. doi:10.1186/s1288 6-019-1204-0

38. Cochener B, Boutillier G, Lamard M, Auberger-Zagnoli C. A comparative evaluation of a new generation of diffractive trifocal and extended depth of focus intraocular lenses. $J$ Refract Surg. 2018;34 (8):507-514. doi:10.3928/1081597X-20180530-02
Clinical Ophthalmology

\section{Publish your work in this journal}

Clinical Ophthalmology is an international, peer-reviewed journal covering all subspecialties within ophthalmology. Key topics include: Optometry; Visual science; Pharmacology and drug therapy in eye diseases; Basic Sciences; Primary and Secondary eye care; Patient Safety and Quality of Care Improvements. This journal is indexed on PubMed

\section{Dovepress}

Central and CAS, and is the official journal of The Society of Clinical Ophthalmology (SCO). The manuscript management system is completely online and includes a very quick and fair peer-review system, which is all easy to use. Visit http://www.dovepress.com/ testimonials.php to read real quotes from published authors. 